\title{
What's the Problem with Learning Analytics?
}

\author{
Neil Selwyn ${ }^{1}$
}

\begin{abstract}
This article summarizes some emerging concerns as learning analytics become implemented throughout education. The article takes a sociotechnical perspective - positioning learning analytics as shaped by a range of social, cultural, political, and economic factors. In this manner, various concerns are outlined regarding the propensity of learning analytics to entrench and deepen the status quo, disempower and disenfranchise vulnerable groups, and further subjugate public education to the profit-led machinations of the burgeoning "data economy." In light of these charges, the article briefly considers some possible areas of change. These include the design of analytics applications that are more open and accessible, that offer genuine control and oversight to users, and that better reflect students' lived reality. The article also considers ways of rethinking the political economy of the learning analytics industry. Above all, learning analytics researchers need to begin talking more openly about the values and politics of data-driven analytics technologies as they are implemented along mass lines throughout school and university contexts.
\end{abstract}

Corresponding author ${ }^{1}$ Email: Neil.Selwyn@monash.edu Address: 19 Ancora Imparo Way, Faculty of Education, Monash University, Clayton, VIC, 3800, Australia ORCID: https://orcid.org/0000-0001-9489-2692

\section{Introduction}

I am pleased to have been invited to contribute some critical thoughts about learning analytics to this journal. This article is therefore written with the intention of adding a few different ideas into the mix and perhaps sparking some debate. Yet, I am aware that this sort of offering can easily be misinterpreted. So, before reading any further, please be assured that this is not intended as a hostile attack on your field. Instead, I am writing as a disinterested outsider with no particular grievance with learning analytics and/or colleagues working in the field. This area of scholarship has thrived without my input up to this point. As such, readers of the Journal of Learning Analytics (JLA) should definitely take this article with a large pinch of salt.

In fact, I expect most readers to pick and choose which elements of this article to take seriously. In one sense, this article contains many arguments that might well appear familiar. The past decade of learning analytics scholarship has benefitted from longstanding discussions of data integrity, ethics, accountability, and the like. By advocating for a more critical take on learning analytics, I am certainly not presuming that this field has never reflected critically on what it is doing. Yet the main aim of this article is to highlight ideas that I do not see being discussed widely. So even if you personally feel that I am "stating the obvious," it might be useful to consider why these issues are not discussed more prominently across the learning analytics community.

So just to restate my position, please do not take any of this the wrong way! I do not claim that the arguments in this article are any better than the arguments already well embedded in learning analytics research. Instead, I hope to offer some additional ideas and different perspectives to play with. The underlying intention of this article is to be constructively critical. I am not expecting to change anyone's mind about learning analytics, but I do hope that it proves productive to view the topic through a slightly different lens ... at least for the next 7000 words.

\section{Learning Analytics - The Need to Be Critical}

While I suspect that some readers might feel that a critical account of learning analytics is unwelcome, it is perhaps more likely that a critical account will simply be considered unwarranted. It might be reasoned, for example, that learning analytics is an emerging area of data science that has only recently started to find its way. As such, more substantial applications of digital technology in education surely currently merit critique. It also might be reasoned that learning analytics applications and systems are inherently harmless. Surely these neutral tools can be used well or badly depending on who is involved.

So, let me start this article by rebuffing these two arguments and, in doing so, spell out why I feel that learning analytics needs to be critiqued as much as possible. First, learning analytics is undoubtedly a key element of contemporary education. This is no longer a sideshow, but a major component of how education is being imagined and enacted. Analytics applications are being rolled-out across university and school systems, meaning that these technologies are now shaping the academic lives and academic outcomes of millions of students. Education analytics is also a fast-growing commercial concern with billions 
of dollars at stake. This area of educational technology is taking hold at a speed and scale that academic researchers might not have noticed ... the genie is well and truly out of the bottle.

Second, we need to challenge the idea that learning analytics is a neutral tool that can be used in any way - for good or for bad, wisely or carelessly, effectively or ineffectively. This is a commonplace and comforting way of understanding any technology. For example, it can be reasoned that "Pencils don't make spelling mistakes; people make spelling mistakes," or the contention that "Guns don't kill people; people kill people." While common-sensical, such logic (wilfully) overlooks the sociotechnical nature of any technology. From a sociotechnical perspective, then, technologies can certainly influence the ways in which people do things, while at the same time being profoundly shaped by those who design, develop, implement, and use them. In this sense, every technology is entwined with a range of social, cultural, political, and economic factors that all play a big part in its design and uptake. As such, we need to think carefully about the ideas, agendas, and values that come to define what any technology is. We also need to think about the ideas, agendas and values that these technologies come to propagate. In short, we need to give much more thought to the ideologies and politics of the technologies we find ourselves using.

So how might this sociotechnical approach apply in the case of learning analytics? The next sections of this article will explore two lines of thought:

- $\quad$ First, what is it that learning analytics technologies end up doing from a critical sociotechnical perspective? How does this differ from what we are usually told learning analytics technologies are intended to do? These questions should get us thinking about the ways in which learning analytics technologies are being designed, developed, and implemented (often unconsciously) to have particular effects.

- $\quad$ Second, what are the "ideologies" and "politics" of learning analytics technologies? In other words, what are the dominant ideas, agendas, and values that have come to define "learning analytics" over the past decade or so, and what problems might lie therein? In what ways are the actual consequences of learning analytics technologies related to broader values and ideologies not explicitly acknowledged in mainstream conversations about data in education?

\section{Questioning the Consequences of Learning Analytics}

Let us briefly consider some consequences seen to result from the implementation of learning analytics in massified higher education and $\mathrm{K}-12$ school settings.

\subsection{A Reduced Understanding of "Education"?}

First is a concern that anything learning analytics claims to "know" about education is likely to be reductive of the actual issues. This relates to a broader suspicion of educational data inevitably being inaccurate, incomplete, poorly chosen, or simply a poor indicator of what it supposedly represents. These gaps and omissions are especially important in terms of modelling what human learners and teachers do. Even the most complex models of "teaching" and "learning" contain significant grey areas. In particular, the core claims of learning analytics to precision, clarity, and predictability feel at odds with the many areas of education that rely on various ambiguities and uncertainties. It can therefore be argued that many elements of education cannot be fully captured and expressed through data processing - even if technically sophisticated approximations are possible. Of course, the field of data science relies on the use of proxy indicators. Nevertheless, many laypeople tend not to treat the data they are presented with as "proxies" or even "indicators." Instead, any data tends to slip quickly into being understood as a direct measure - especially when presented conclusively in the form of dashboards, traffic lights, and other visualizations. These concerns stretch well beyond conventional notions of data validity, and instead challenge the appropriateness of using data at all to model educational processes and practices adequately.

\subsection{Ignoring the Broader Social Contexts of Education?}

Second are growing concerns that learning analytics suffers from an inevitable lack of common-sense understanding and nuanced awareness of educational contexts. This is a common criticism of even the most sophisticated data-based technologies. As Fei-Fei Li (2017) wryly reminds us, "the definition of today's AI is a machine that can make a perfect chess move while the room is on fire." Thus considerable doubts remain over the extent to which learning analytics systems can ever appropriate what is going on in the "real world" contexts within which specific learning episodes are situated. In particular, it can be argued that learning analytics grossly underestimate the social complexity of classrooms, schools, and the complicated lives that students lead. Echoing Murray Goulden's distinction between "technologically smart" but "socially stupid" systems, the concern persists that there are not enough data points in the world to adequately capture the complexities and nuances of who a student is, or how a school functions.

\subsection{Reducing Students' and Teachers' Capacity for Informed Decision-Making?}

Third are concerns over explainability and "black-boxing." While learning analytics are often framed in terms of supporting 
human decision-making, most often these technologies are used to direct (if not determine) human decision-making. These systems separate teaching and learning processes into different components to model past behaviours with a view to recommending future actions. As such, learning analytics systems arguably run the risk of diminishing the ability of students and teachers to exercise judgment and expertise in the overall process. Moreover, this lack of overall comprehension is compounded by an inevitable lack of explainability. In short, as data-driven systems become more complicated, it becomes increasingly difficult to work out the rationales behind any outputs that these systems produce (Ivarsson, 2017). Even the programmers and engineers who design analytics systems soon struggle to isolate and explain the reasons that their system has for any particular action. Again, this logic sits uneasily with established ways of doing things in education. Teaching and learning are considered processes where people need to know why as much as they need to know what. Simply being directed what to do next (even with a cursory pre-scripted "explanation" based on a limited set of variables) does not constitute "learning" or "teaching" in its fullest dialogic sense. Instead, it can be argued that these systems and applications inevitably detract from students' and teachers' overall control of the work they are doing, while also undermining professional judgement and expertise.

\subsection{A Means of Surveillance Rather than Support}

Similar to this slippage between guidance and direction are concerns over the line between being "assisted" and being "supervised." School and university contexts are increasingly predicated around performance management, measurements, metrics, auditing, and accountability. With learning analytics applications generating data purporting to relate to a wide range of behaviours, actions, inferred moods, and assumed intentions, it is likely that data flows will extend well beyond a specific learning analytics system and the individual student and teacher. Thus any promises of learning analytics acting to support a student's learning sit uneasily with broader concerns over the "dataveillance" of teachers and students. The concern here lies with the secondary (re)uses of learning analytics data by institutions and other "third parties." For example, learning analytics offer a ready input into the "performative management" of teachers and the "statistical profiling" of students in terms of their associations and linkages with others. Even the most learning-focused application runs the risk of "mission-creep" in being co-opted into broader institutional purposes.

\subsection{A Source of Performativity}

Fifth are concerns with the ways in which learning analytics influence what students, teachers, and schools do. While not designed to be "evaluatory" per se, learning analytics technologies are nevertheless being implemented in school and university contexts shaped by evaluation, testing, measuring, ranking, and performance comparison. The data generated through learning analytics technologies therefore fits neatly with the prevailing logic of students and teachers having to account for their work, and thus feeling the need to demonstrate that they are working effectively. It can be argued that learning analytics become inevitably embroiled in the "high stakes" environment of contemporary education. Students will act in ways that "please" the indicators, or else attempt to "game" the system logic. Teachers will work to "second guess" what the system will reward; for example, "teaching to the algorithm" in a similar manner to the well-established phenomenon of "teaching to the test." When working in educational settings overlaid with analytics, it is inevitable that teachers and students will focus on the things being analyzed.

\subsection{Disadvantaging Large Numbers of People}

The issues raised so far all point to broader concerns that, fundamentally, learning analytics work to (dis)advantage some groups of students and teachers more than others. A central concern here relates to the reproduction of existing social inequalities as well as the generation of new forms of inequality through data-driven processes. For example, the argument is increasingly being made that data-driven systems exacerbate discriminatory decision-making in favour of those social groups most represented in the systems' datasets (Noble, 2018; Eubanks, 2018). Moreover, at a basic level, concerns are also raised over the unequal agency that individuals and social groups have when engaging with digital data (see Selwyn, 2015). Put crudely, a distinction can be made between those who have the ability to "do data" as opposed to those who merely have data "done to them." This spans from the majority of individuals who simply create data for others to process (and are largely unconscious of doing so); those who create data but are often conscious of doing so; those who have the means to collect data; and finally those who have the expertise to analyze data. Clearly, these different groups are ordered along lines of technical and statistical expertise. Yet such hierarchies also map onto existing power differentials and unequal social relations. In short, then, concerns can be raised over the inequitable ways in which analytics systems are encountered and experienced by different groups of students and teachers.

\subsection{Serving Institutional (Rather than Individual) Interests}

Finally, is the underlying sense that learning analytics are implemented primarily to benefit the needs of institutions rather than individuals. As such, learning analytics are seen as part of the general societal encroachment of business analytics, consumer 
analytics, healthcare analytics, and so on. There is growing resentment of organizations "us[ing] our data to invisibly shunt us in directions that may benefit them more than us" (Singer, 2018). In a manner similar to these other forms of analytics, it can be argued that the "end users" of learning analytics are not students or teachers per se. Instead, these products work primarily in the interests of school leaders and administrators, software vendors, and a range of other third parties who stand to benefit from claims to know how learning takes place. It might even be reasoned that the end users of learning analytics are increasingly machine-based rather than human. In this sense, the main users of the outputs from learning analytics systems are likely to be other analytics systems - with data being passed around, recirculated, recombined, and (re)processed by other algorithms, systems, and bots. All told, there is an emerging suspicion (warranted or not) that students are not the primary beneficiaries of the learning analytics technologies they are subjected to during their school or university education.

\section{Questioning the Values of Learning Analytics}

These brief descriptions all illustrate key strands of unease (if not hostility) relating to the implementation of learning analytics in schools and universities. As might be expected, the issues just raised contrast with the outcomes usually celebrated in discussions of learning analytics. In fact, many of these contentions reflect a general suspicion of the broad idea of "learning analytics" and the values and assumptions implicit in the learning analytics project. In addressing the second question posed towards beginning of this article, the following criticisms can thus be raised.

\subsection{A Blind Faith in "Data"}

One of the core tenets of learning analytics is that data (in particular, data derived from digital technologies in educational contexts) can 1) be used to model learning processes that have taken place; and 2) thereby provide a basis for making decisions regarding future learning. Herein lies a major tension. On one side are "dataphiles" who consider that everything is quantifiable, calculable, and potentially party to statistical control. On the other side are "data sceptics" who feel that education is an area where this logic is not appropriate. Indeed, many people contend that education — and in particular learning and teaching processes - simply cannot be subjected to what Dave Beer (2018) terms the "data gaze." Some commentators are genuinely perturbed by claims of being able to infer information about students from typed interactions to discussion forums or from tracking eye movements when using a computer.

Readers of JLA may well be familiar with (and perhaps weary of) such contentions, but these arguments remain a central part of the pushback against learning analytics as it becomes implemented more widely in schools and universities. In one sense, this stems back to the irreconcilable tension between objectivist and constructionist ontological positions. In short, plenty of people outside the learning analytics community are unlikely ever to accept that learning and teaching can be objectively defined, measured, and modelled. Instead, all forms of data are socially constructed and any instance of data processing or analysis is inherently shaped by a priori theories, ideas, interpretive structures, and assumptions. Thus as Cathy O’Neil (2016) puts it (echoing many others before her), "when you hear someone say 'data are objective' that just means they got to choose the definition of success." Whether or not one agrees with this sentiment, any claim to be able to fully represent something as complex and emotive as "learning" will obviously be hotly contested.

\subsection{Concerns over the Data Economy}

For many critics, the benefits of learning analytics are mitigated by the increasingly exploitative conditions of the data economy. While it is convenient to frame "learning analytics" in abstract terms, in reality this is becoming an industry that involves a complex range of technologies and actors - from data storage centres in Idaho to salespeople in Singapore. Rather than being neutral intermediaries, these can all be seen as part of a global "data economy" hinged on the extraction of economic value from the collection and processing of data resulting from digital technologies and the people who use them. As such, it could be argued that "learning analytics" needs to be understood primarily as a fast-growing and increasingly lucrative worldwide industry. Of course, the market for education data is only a small part of a wider "social quantification sector" led by massive corporations on the scale of Facebook and Acxiom Equifax (see Couldry \& Mejias, 2019). Nevertheless, educationrelated data (alongside data relating to health, finance, and consumer behaviour) remains a highly profitable form of data extraction and commodification.

In this sense, every user of a learning analytics system is essentially performing an unpaid form of "digital labour" by generating data that is ultimately of value for the system producers and vendors. Even if student data is not sold directly to third parties, the accuracy (and therefore value) of these systems is refined and improved with each additional case processed. In unknowingly adding value to the systems they are using, students and teachers are essentially engaged in an exploitative form of "compliance labour" (cf. Iveson, 2017). In fact, since few students have any real choice about using the technologies implemented in their schools and universities, this might be most accurately described as "coerced labour." All told, the suspicion remains that students and teachers do far more for the developers and owners of commercial learning analytics systems than the systems do for them. 


\subsection{The Limits of Free "Choice" and Individual Agency}

Concerns regarding the focus of learning analytics on influencing individual decision-making regarding learning can also be raised. Rather than working to support "learning" per se, learning analytics is essentially a form of individually focused behaviour management - sometimes termed "nudging" people's decision-making and action. This chimes with what Judy Wajcman (2019, p. 8) terms a "new behaviourism" in many different areas of everyday life, emerging from the elision of "big data" sets and algorithmic psychometrics. In this manner, learning analytics fits with a recent trend to frame individuals as purposive and knowledgeable actors whose behaviour "can be steered and nudged in ways both personally gratifying and economically profitable" (Fourcade \& Healy, 2017, p. 20).

These individually focused, affectively centred ambitions raise a number of problems. First, students are not always able to act in agentic ways and simply "change" their behaviours and emotions if given appropriate feedback. For example, an individual's "states" and "traits" are not wholly self-determined and certainly not always related to the current moment. For many reasons, someone might come into a learning episode in a "disengaged" state that no amount of responsive feedback from an analytics system will alter. Relying on analytics for prompts and guidance arguably does not necessarily strengthen an individual's capacity to make future decisions for themselves. As Selena Nemorin (2016) argues, the logic of "nudging" in areas such as consumer behaviour usually does not seek to develop an individual's capacity, but instead strives to exploit their susceptibility to external influences. Having one's instincts shaped and nudged might well depower and infantilize students. In this sense, continuous monitoring and nudging throughout one's educational engagement could be undesirable and ultimately unhelpful.

\subsection{An Implicit Techno-Idealism}

Finally, is unease with the implicit emphasis throughout learning analytics on digital technology as a ready means of addressing social issues. This has been characterized by Evgeny Morozov as techno-solutionism - that is, a belief that "the idea that given the right code, algorithms and robots, technology can solve all of mankind's problems, effectively making life 'frictionless' and trouble-free" (cited in Tucker, 2013). In particular, this view of technology as an agent of change promotes what Wajcman (2019) describes as an "engineering model" that conceives of individuals and the social systems they live in as essentially programmable machines that can be engineered to operate effectively given the correct inputs.

As implied earlier, concerns remain that this technology-led mentality grossly underestimates the social complexity of educational settings, meaning that any long-term outcomes of learning analytics are unlikely to match the initial enthusiasms of developers. This is a well-noted limitation of the application of "new" technologies in educational contexts. Christo Sims (2017) points out that educational technology innovations are often driven by a "sincere technological idealism," with technologists genuinely expecting to make a difference and "do good." However, Sims reasons that this tendency to approach education through a technical mindset engenders "tunnel vision" on aspects of education that fit with the tools being developed. This narrow approach often marginalizes any consideration for broader social contexts and structural inequalities that shape much of what takes place in schools and universities. In this sense, regardless of their initial good intentions and technical sophistication, technological innovations in education rarely end up fulfilling their initial expectations and promises.

\section{Potential Areas for Change}

This article has so far presented two related sets of contentions. First are emerging concerns around the "real-life" consequences of implementing learning analytics within contemporary higher education and $\mathrm{K}-12$ school systems. These suggest that analytics-driven education runs the risk of being reductive, non-representative, unjust, and exploitative. Second, this article has also pointed to a set of problematic values, assumptions, and ideologies that lie at the heart of the learning analytics approach and its implicit emphasis on using digital data to drive educational improvements. Of course, schools and universities have faced increased pressure over the past twenty years to embrace "datafication" in the form of the measurement and metricization of outcomes, alongside the data-driven auditing and accountability of individuals' work. In this sense, learning analytics is not unique in either its logics or its consequences. Yet even within these broader conditions, many are particularly unhappy with what "learning analytics" stands for and with its end results.

So what might be done? Here, taking a sociotechnical approach to learning analytics offers some room for manoeuvre. One of the ideas to emerge from this article's initial discussions is that the nature and form of any technology - pencil, gun, or learning analytics - is not set in stone. Instead, all technologies are characterized by some degree of contestation and "interpretive flexibility," especially during initial stages of design and implementation. From this perspective, there are no predestined ways in which any technological artefact should be designed or used. Indeed, designs and uses will vary between different groups and contexts, often resulting in conflict between competing views and ideas. This is illustrated in sociological studies of the historical development of what now seem mundane artefacts (such as bicycles and lightbulbs), showing that the 
diversity of interpretations of any technology is likely to diminish over time, often until its agreed meaning reaches a stage of "stabilization" and eventual "closure" (see Selwyn, 2019).

The challenge now facing the learning analytics community appears straightforward. If the arguments made so far are taken seriously, then it seems that the "real-world" use of learning analytics is becoming stabilized around a set of rather problematic values and understandings. As such, the case can be made for re-imagining and re-engineering these core values, assumptions, and ideologies. In practical terms, this suggests designing, developing, implementing, and enacting new forms of learning analytics that embody these values in more explicit, up-front ways. How might this be done? What follows is a brief summary of some speculative suggestions for change. These ideas are by no means fully formed, but perhaps they point to some alternate possible "flavours" of learning analytics that we might prefer working towards.

\section{1. $\quad$ Rethinking the Design of Learning Analytics}

First are suggestions regarding the (re)design of learning analytics technologies. For example, inspiration might be taken from so-called "socially sympathetic" design approaches. This involves designing systems and applications in ways that are mindful of the different social contexts in which they are likely to be used, as well as the diverse needs and rights of users. Above all, this implies ensuring the informed engagement of individuals interacting with these systems. This approach is sometimes described as "user-respectful" design (as distinct from "user-friendly" or "user-centred"), which foregrounds issues relating to privacy, security, and user rights.

One important set of principles to consider relate to increasing the transparency of learning analytics technologies. This can be as simple as ensuring that their coding and programming is made transparent and accountable to users. That means designing systems that display their assumptions and biases, and make clear who is responsible for each system and its outcomes. The growing interest in "white-boxing" applications, for example, shows a preference for the criteria applied in any automated decision-making process being revealed in ways that make sense to non-specialist users. This allows "individuals to challenge, or at the very least understand, how decisions about them are made" (Tene \& Polonetsky, 2014, p. 99).

One suggestion along these lines is to design easily explainable learning analytics systems that are also clearly accountable. Reidenberg and Schaub (2018) suggest key elements to such algorithmic accountability might include giving users the right to inspect what decisions have been made, understand how these decisions were reached, receive validation of the legitimacy of these decisions, and/or be able to correct or amend these decisions. Moreover, as Lilly Irani reasons, any algorithmic system is also a bureaucratic system making choices previously the responsibility of a human (Smith, 2018). As such, the idea of assigning human responsibility to learning analytics systems makes good sense. This suggests designing features that allow the decisions reached by any learning analytics technology to be attributed to their original author and/or institutional endorser.

Another important design principle is giving increased control to students who find themselves using learning analytics technology. Possibilities here include designing learning analytics systems to inform users of how their data is being used, thereby allowing students to pose the basic question "Who is benefitting from my behavioural data?" (Howard, 2017). This might take the form of "live" disclosure of the recirculation of user data or the provision of yearly audits of when and how an individual's personal data has been used. The principle of active, informed consent complements these suggestions for informed engagement. For example, rather than students being permitted to "opt-out" of using learning analytics systems during their school or university studies, it might be more appropriate for learning analytics systems to be designed on an "optin" basis. Alongside any initial decision to opt-in, students should have a right for selective (dis)engagement — in other words, having the choice to "pause" the tracking and collection of their data at any point.

Perhaps the most ambitious design suggestion is for applications and systems that allow students to configure their own analytics. This would involve presenting users with details of the full range of available data and associated analytic tools to process their preferred computations and configurations of the data. At the very least, it seems appropriate to design systems that permit students to review, configure, and edit their profiles — that is, to have some curatorial control over what the system "indicates" about them. That said, student interest in education data should not be assumed to lie solely with data relating to their personal situations. Instead, it might be argued that the most pressing questions that students (and teachers) want to ask about their collective educational experiences and conditions are not being addressed through the individualized data currently being fed back to them. If learning analytics are genuinely intended to work for the benefit of students, then providing full access to available data and control over its processing seem like obvious ways of prompting more just and liberatory outcomes (see Shelton, 2017).

\subsection{Rethinking the Economics of Learning Analytics}

Of course, many aspects of learning analytics cannot be improved through different approaches to design. In particular, the reconfiguration of the economics and politics of learning analytics is a matter of long-term structural change and adjustment. In this sense, a second set of suggestions relates to the "data economies" within which learning analytics is implicated. As contended earlier, the generation of learning-related data could be described as essentially a process of generating excess value 
and profit for the producers and vendors of learning analytics systems. In this sense, the rights of students arguably extend beyond being users or consumers of learning analytics systems. Instead, students have a valid claim to the status of being workers and producers (Iveson, 2017). In short, if students' everyday uses of learning analytics systems result in their increased value and profitability, then it seems fair that these profits be shared with students.

One suggestion along these lines is to give students ownership of their own data — what could be termed "personal data sovereignty" (Jarchow \& Estermann, 2015). For example, students might be positioned as equal participants in the "personal data marketplace" through being given proprietary rights over their data (Robinson, 2017). This would give each student the option to sell their data back to the system owners, or perhaps donate their data to non-profit actors such as university research or government agencies. Alternately, rather than placing a burden on individual students to engage in the self-management of data, students might participate in data-sharing arrangements such as the MiDATA co-operative platform for the redistribution of health-related data. Another suggestion is establishing "personal data brokers" to work as intermediaries managing an individual's data in much the way that an accountant deals with personal tax returns (Obar, 2015).

The economics of learning analytics might be more fairly configured with profits redistributed in many different ways. Aside from data sovereignty, proprietary learning analytics platforms could pay students a wage for their efforts. Alternately, governments and companies might enter into "tithe" arrangements where $10 \%$ of any profits associated with the data generated return to that school district or jurisdiction. These proposals might appear somewhat clumsy, but they highlight the moral ambiguity of students generating profits that flow directly back to the platform provider.

\section{3. $\quad$ Rethinking the Governance of Learning Analytics}

These latter suggestions also point to the need to pay close attention to the governance of the learning analytics industry. First, is rethinking the role of commercial actors in the governance and stewardship of learning analytics. As demonstrated in recent controversies where various "Big Tech" actors have sought to avoid restriction of their activities in the form of taxation, data protection regulation, and unionization, this is a contentious area. While there is a growing acknowledgment within the IT industry of the need for some form of "corporate oversight," this has not proven simple to establish in practice. Similarly, whereas large IT industry actors have traditionally been willing to place some of their education-related activities under the aegis of "corporate social responsibility," this is unlikely to be an effective means of ensuring that commercial learning analytics products embody educational values and the public good.

Instead, "corporate consciousness" might be fostered from within commercial providers of learning analytics. In particular, this could involve workers collectively advocating for value-driven corporate practices. The recent successes of Google employees agitating to cease the corporation's work on military AI for the Pentagon and censored-search algorithms for China provide inspiration. Smaller companies, contractors, and suppliers might choose to refuse to work with larger IT firms seen to exploit education systems and applications. Actors working within the analytics industry might well influence the development of publically responsible forms of learning analytics. After all, what is advantageous for shareholders or funders may not be so advantageous for students or teachers.

A strong case for increasing the role of government in stewarding the implementation of learning analytics in public schools and universities can also be made. Governments do not have a strong track record in understanding (let alone leading) the development of digital technology. Yet in light of recent IT industry controversies about platform monopolies, mass data breaches, and negligence regarding worker and consumer rights, there is growing need for establishing strong "tech-savvy" government involvement in shaping digital technology use for the public good rather than predominantly for profit. The use of digital technology in education seems an obvious central component of this.

In terms of learning analytics, then, government agencies might play a key role in evaluating new data-driven systems and applications proposed for use in public education, ensuring that any learning analytics product meets designated levels of data quality and minimal bias. Reidenberg and Schaub (2018) suggest that government agencies take responsibility for establishing procurement criteria for guidance to public schools when adopting systems. The same agencies could monitor the performance of these systems once put into place, and recommend alternate approaches where appropriate. For example, in the same way that governments assume responsibility for licensing classroom teachers, government agencies could license individual learning analytics applications and systems. Conversely, learning analytics systems should be "struck off" an approved register if deemed not to meet the required levels of performance. Alternately, the producers of learning analytics systems could be held legally accountable for their actions in the same way that examination boards are. Such issues are being given serious consideration in areas such "precision medicine" and automated transportation. There is no reason that data-driven education should not have the same levels of oversight and accountability.

\subsection{Towards Better Public Understanding of Learning Analytics}

Underpinning all these suggestions is the need to support expanded public, policy, and professional understandings of learning analytics and its constitutive effects in education. This points to the value of developing expansive, broad-minded public 
conversations about the use of data in education, and the specific implications of the broader use of analytics-driven education. In short, if meaningful changes are to take place, this requires better awareness and understanding of data-related issues amongst educational professionals and the public, leading to sustained debate over what ends societies want data-driven education to achieve.

Supporting sustained public conversations about the issues raised in this article would not be an easy task. Such conversations would need to involve a range of actors - from school leaders and university administrators who make decisions about the procurement of these systems, to students and parents directly implicated in their use. These conversations must begin with basic matters of what "learning analytics" is, as well as the statistical and data literacies required to engage with these systems. In addition, these conversations need to foster the development of a critical conscious-raising about personal data - i.e., understanding the broader uses and outcomes resulting from the circulation of personal data, and a critical awareness of how third-party uses might be resisted and perhaps repurposed (see Pangrazio \& Selwyn, 2018).

One useful initial focus for these conversations might be the "ethics" of learning analytics, and the moral implications of the increased use of data in education more generally. Indeed, ethics should arguably be a collective responsibility, not left to developers to decide. This would require ongoing public conversations about learning analytics in terms of power, control, and disparities in access and outcomes. As Kate Crawford (2017) reminds us, "often when we talk about ethics, we forget to talk about power." Thus, these conversations would need to move beyond talking about the ethics of learning analytics purely in terms of protecting personal data and avoiding harm. Instead, conversations that recognize the power imbalances inherent in learning analytics, and practical ways of addressing these issues, are required. Only by talking through the implications of increased analytics use in education can we work collectively toward better ways of using digital data in teaching and learning that do not engender the compromises and injustices highlighted earlier.

\section{Conclusion}

This article has briefly sketched out some emerging critical concerns as digital data becomes ever more embedded in education. In particular, I have attempted to look beyond the assertion that learning analytics is essentially apolitical and objective. Instead, it has framed the use of data in education in what are "always intensely political and normative decisions" (Shelton, 2017, p. 24). Beyond the prevailing hype of student success systems and lifelong learning analytics lie genuine concerns that learning analytics might entrench and deepen the status quo, disempower and disenfranchise vulnerable groups, and further subjugate public education to the profit-led machinations of the booming data economy. While you might not agree with every one of these contentions, they all illustrate the inherently political nature of learning analytics. To reiterate, I do not expect readers of JLA to agree with everything written here. Yet it might be useful to reflect on which of these contentions do resonate, and then take these thoughts further into your own future work.

As well as pointing out problems, the article has briefly considered some possible areas of change. These include, for example, the design of analytics applications that are more open and accessible, that offer genuine control and oversight to users, and that "better reflect qualitative dimensions of [students'] lived reality." This also includes rethinking the political economy of the learning analytics industry. These suggestions are not offered with the expectation that they would be straightforward to implement or easy to achieve. On the contrary, I am aware that these changes might appear practically impossible to enact. In this sense, perhaps the most immediate task for learning analytics practitioners is simply to begin talking more often (and more openly) about the problematic aspects of learning analytics arising from the mainstream implementation of these technologies in "real-life" school and university contexts.

This task of stimulating a critical discourse might be one of the most useful immediate challenges for the academic learning analytics community to take up. As the development and implementation of learning analytics technologies increasingly become the preserve of large-scale commercial interests, there is diminishing need for academic research or university "R\&D" in this area. University academics may have played a leading role in establishing the concept of learning analytics, but they are increasingly less involved in its development, production, implementation, and use. As such, academic communities such as JLA, LAK, and SoLAR are now well-placed to assume an expert, "critical-friend" role in supporting the learning analytics industry and the schools and universities that adopt their products. Academics are certainly well resourced in terms of time, interest, and ideas to push back against the hype that is beginning to surround learning analytics, and to point to potentially useful ways of "thinking otherwise." In this sense, the hard work of learning analytics scholarship has perhaps only just begun.

\section{Declaration of Conflicting Interest}

The author declared no potential conflicts of interest with respect to the research, authorship, and/or publication of this article.

\section{Funding}

The author(s) declared no financial support for the research, authorship, and/or publication of this article. 


\section{References}

Beer, D. (2018). The data gaze. New York: Sage.

Couldry, N., \& Mejias, U. (2019). The costs of connection. Palo Alto CA: Stanford University Press.

Crawford, K. (2017). Why AI is still waiting for its ethics transplant. Wired, 1 Nov. 2017. www.wired.com/story/why-ai-isstill-waiting-for-its-ethics-transplant/

Eubanks, V. (2018). Automating inequality. New York: St. Martin's Press.

Fourcade, M., \& Healy, K. (2017). Classification situations: Life-chances in the neoliberal era. Historical Social Research/Historische Sozialforschung, Vol.42, No. 1 (159), Markets and Classifications. Categorizations and Valuations as Social Processes Structuring Markets (2017), pp. 23-51

Howard, P. (2017). Is social media killing democracy? Computational propaganda, algorithms, automation and public life. Inaugural lecture to the Oxford Internet Institute, 15 June 2017. www.youtube.com/watch? $=\mathrm{J} 1 \mathrm{kXdA61AQY}$

Ivarsson, J. (2017). Algorithmic accountability. Lärande, 2 May 2017. http://lit.blogg.gu.se/2017/05/02/algorithmicaccountability/

Iveson, K. (2017). Digital labourers of the city, unite! In J. Shaw \& M. Graham (Eds.), Our digital rights to the city (pp. 2022). Oxford, UK: Meatspace Press.

Jarchow, T., \& Estermann, B. (2015). Big data: Opportunities, risks and the need for action. Berner Fachhochschule, EGovernment-Institut.

Li, F. (2017). Put humans at the centre of AI. MIT Technology Review, 9 Oct. 2017. https://www.technologyreview.com/s/609060/put-humans-at-the-center-of-ai

Nemorin, S. (2016). Neuromarketing and the "poor in world" consumer. Consumption Markets \& Culture, 20(1), 59-80. https:/dx.doi.org/10.1080/10253866.2016.1160897

Noble, S. (2018). Algorithms of oppression. New York: New York University Press.

Obar, J. (2015). Big data and the phantom public: Walter Lippmann and the fallacy of data privacy self-management. Big Data \& Society, 2(2). http://dx.doi.org/10.1177/2053951715608876

O’Neil, C. (2016). Weapons of math destruction. New York: Broadway Books.

Pangrazio, L., \& Selwyn, N. (2018). "Personal data literacies": A critical literacies approach to enhancing understandings of personal digital data. New Media \& Society, 21(2). http://dx.doi.org/10.1177/1461444818799523

Reidenberg, J., \& Schaub, F. (2018). Achieving big data privacy in education. Theory and Research in Education, 16(3). http://dx.doi.org/10.1177/1477878518805308

Robinson, S. (2017). What's your anonymity worth? Digital Policy, Regulation and Governance, 19(5), 353-366. https://dx.doi.org/10.1108/DPRG-05-2017-0018

Selwyn, N. (2015). Data entry: Towards the critical study of digital data and education. Learning, Media and Technology, 40(1), 64-82. https://dx.doi.org/10.1080/17439884.2014.921628

Selwyn, N. (2016). Is technology good for education? Cambridge, UK: Polity Press.

Selwyn, N. (2019). What is digital sociology? Cambridge, UK: Polity Press.

Shelton, T. (2017). Re-politicizing data. In J. Shaw \& M. Graham (Eds.), Our digital rights to the city (pp. 24-27). Oxford, UK: Meatspace Press.

Sims, C. (2017). Disruptive fixation: School reform and the pitfalls of techno-idealism. Princeton, NJ: Princeton University Press.

Singer, N. (2018). Just don't call it privacy. New York Times, 22 Sept. 2018. www.nytimes.com/2018/09/22/sundayreview/privacy-hearing-amazon-google.html?smid=tw-nytopinion\&smtyp=cur

Smith, A. (2018). Franken-algorithms: The deadly consequences of unpredictable code. The Guardian, 30 Aug. 2018. www.theguardian.com/technology/2018/aug/29/coding-algorithms-frankenalgos-program-danger

Tene, O., \& Polonetsky, J. (2014). A theory of creepy: Technology, privacy, and shifting social norms. Yale Journal of Law and Technology, 16(1), article 2.

Tucker, I. (2013). Evgeny Morozov: We are abandoning all the checks and balances. The Guardian, 9 Mar. 2013. www.theguardian.com/technology/2013/mar/09/evgeny-morozov-technology-solutionism-interview

Wajcman, J. (2019). The digital architecture of time management. Science, Technology, \& Human Values, 44(2). http://dx.doi/org/10.1177/0162243918795041 